\title{
Immigration in the Mediterranean Cities: Comparison between Italy and Turkey
}

\author{
By Dora Francese* \\ Funda $U z^{\ddagger}$ \\ Emanuela Adamo ${ }^{+}$
}

\begin{abstract}
Immigration has involved the transformation and development of cities both in Europe and Asia, by means of inhabitants' integration. New kinds of people create changes in the daily life of receiving society, altering morphology and city architecture. Cases-studies (Italy, Turkey) of sustainable temporary lodgings, used in emergency and after, also aiming at establishing "open spaces" more pleasant, are shown. In the "transit city" Istanbul, migrants coming from Iraq, Africa and Syria left social, cultural and historical signs in the spatial structure. In the designing of spaces for mobility, leisure, and events, quality and form rather than only help to perform particular functions, should be considered. In both countries, public-space projects - participated should be concerned about conflict and solidarity, stability and dynamism, connection and distance. Due to immigration, changes in society and urban spaces could stimulate integration between citizens and new populations, transform the city and promote knowledge of local cultural heritage.
\end{abstract}

Keyword: city transformation, collective integration, social space, temporary lodgings

\section{Introduction}

The question of immigration can be viewed from different perspectives: in these notes the city transformations due to this phenomenon is briefly faced, in terms of repercussions on the urban open space redefinition. The comparison between the Italian and Turkish situation, mainly in the big cities, can show how different phenomena lead to various responses of designers, of politicians and of people, both local inhabitants and non-native immigrants. The open space becomes the land for confrontation as well as for argument, thus carrying with it the question of the technological means for transforming the places. Whenever the application is sustainable, soft and respectful of the cultural as well as natural milieu, the resulted interventions show a better social value and a greater potential for integration between immigrants and natives. In particular, since one of the major problem for the immigrants is that of the

\footnotetext{
${ }^{*}$ Professor, University Federico II, Italy.

*Associate Professor, "İstanbul technical University", Turkey.

${ }^{+}$PhD Student, "Federico II" University, Italy.
} 
dwelling, the open space surrounding the social housing settlements should become more efficient and should provide higher quality of life. This means that the infrastructures, the facilities and the green areas become the main meeting point for the various populations. In Italy the situation is complex, relatively new (it can be remembered that the Italians were themselves immigrants in the last century) and only in the North some attempts have been made so as to face the question, whilst in Turkey immigration is a political and economic question actually innate in the country itself.

The city then changes according to this phenomenon, mainly due to the fact that new requirements are born according to the incoming of new populations and new cultures.

\section{The Comparison between the Italian and the Turkish Situation}

\section{The Italian Case Study}

Migration and immigration are not a new phenomenon; they are embedded in the history of human societies. International migration in its various forms once again hit the headlines across Europe. It is part of a transnational revolution that is reshaping society and politics around the globe (Castells and Miller 2010).

South Italy is a transition zone for the immigrants, both for men and women, coming from the Mediterranean zones and directed to north Europe, where the quality of life and the opportunities to find a job are greater.

However, the phenomenon of the immigration in one of the southern Italian regions - Campania - is lower than in the whole peninsula of about $3 \%$. Especially women are mostly established in the coastal zones, such as Naples and its surrounding areas. For this reason, the number of immigrants is continuously increasing in comparison with the national data.

Figure 1. Immigration in Campania

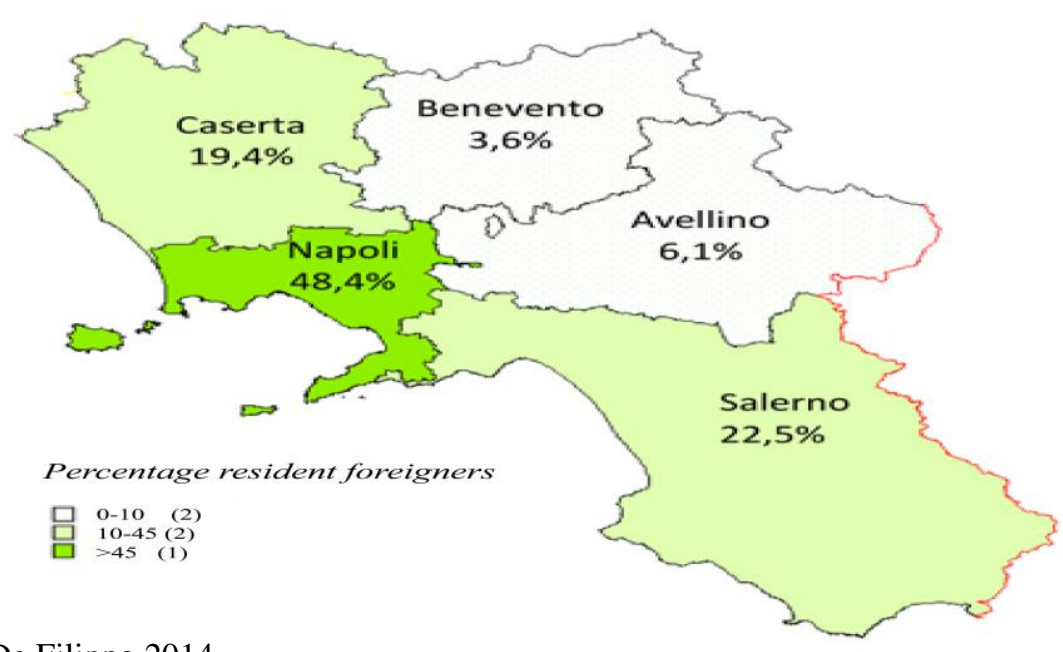

Source: De Filippo 2014. 
This behaviour has changed the cities, both from a demographic statistics and a morphological point of view, for the following reasons:

- the new communities are established in particular districts;

- they were able to integrate with the city more easily in zones like stations or subways;

- those zones allow them to have a house at a reduced renting cost (Musella et al. 2008).

In the last thirty years, the city had a reckless building development as an effect of the large phenomenon of immigration that strikes the whole region. The latter has resulted in a common solution concerning the transformations of the cities as Naples and other cities in the North of Italy, like Milan, subject to the immigration itself.

In order to achieve a common solution, an application has been proposed under the European JPI Programme in 2013, where the focal points have been drawn as follows:

- to turn the urban areas into centres of innovation and technology;

- to ensure cohesion and social integration;

- to take advantage of the technical solutions in order to bring to fruition the urban systems (transport, energy, water, telecommunications ...) in an efficient and sustainable way. ${ }^{1}$

According to the above mentioned assumptions, a social housing settlement in Milan has been studied, being a city with great capability to accommodate such structures and with problems regarding the immigration which are common in Italy as a whole. The place under study is in the district of Gallarate, North of Milan, where the project has previewed the services and the infrastructures that allow the space to be shared among the various populations. The park and public gardens, with the presence of both greenery and small markets, are the most important factors that allow the development of this new ideal. In fact, they guarantee the interaction between the children, the commercial activities and the people that, rather than introducing only Italian traditional exhibitors, can show the products of different nationalities enabling the knowledge of these new cultures as well as the opportunity to experience them.

\footnotetext{
${ }^{1}$ Urban Europe creating attractive, sustainable and economically viable urban areas.
} 
Figure 2. Masterplan in Gallarate Area

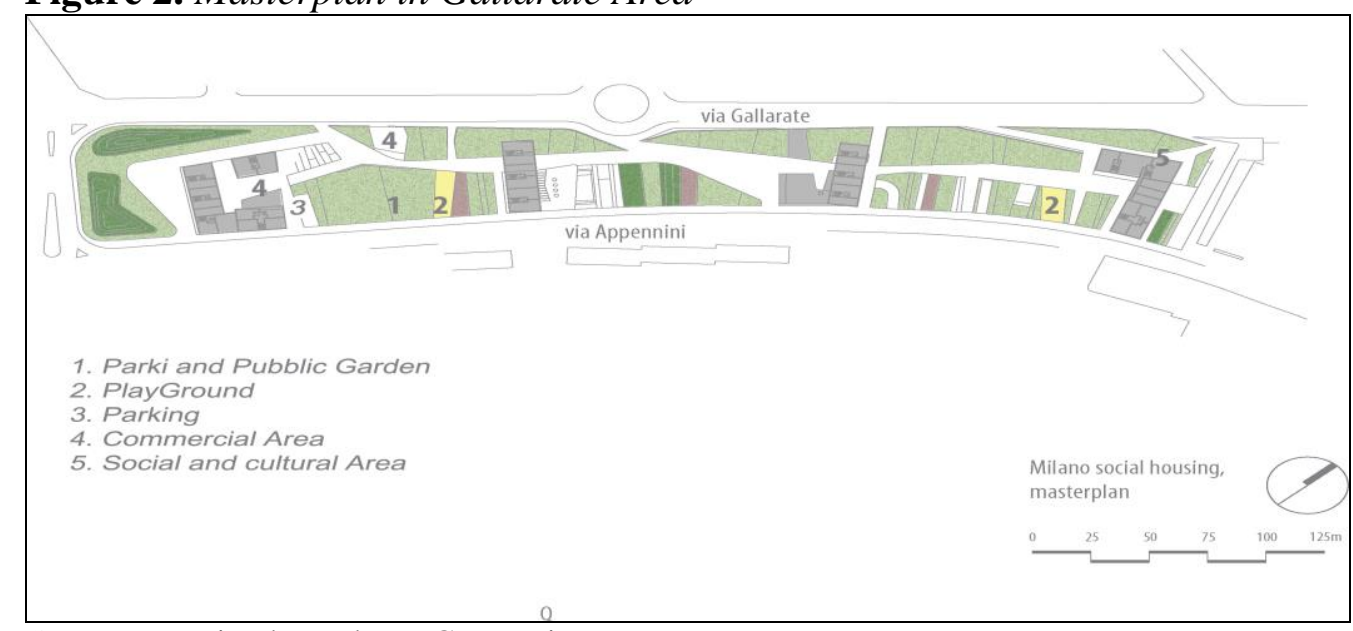

Source: Drawing by Roberta Camaggio.

In conclusion, the following targets have tried to be achieved:

- creation of services and entertainment structures in the proximities;

- assurance of higher life quality according to the real population's needs;

- opposition to social isolation;

- support for social integration;

- saving of energy resources.

\section{The Turkish Case Study}

Migration is a single word collectively expressing individual or mass translocation, from the movement of nomadic groups to a national and international scale. It reveals that all these actions represent a social condition in Turkey. Therefore the term is a sign of resistance to understand certain aspects of change and transformation.

The immigration is the movement of people into another country or region of which they are not native in order to settle there. Immigration is a result of a number of factors, including economic and/or political reasons, family re-unification, natural disasters or the wish to voluntarily change one's surroundings (Joppke 1999).

The public opinion in Turkey often considers immigration as a process of migration from the village to the city, and as such, a component of domestic migration. Both from a statistical point of view, and from the perspective of urban administration and everyday life of urban inhabitants the interest it receives is not justified. Whilst the process of international migration finds strong repercussions both in academic and public circles in many countries (Iran, Iraq, Syria, Post Soviet Union...), Turkey does actually have a past and present related to international immigration itself (Özlüdil 2008).

Istanbul is considered as the city with the largest influx of immigrants in Europe, because its unique position as a booming cultural and economic hub 
has established it as a centre for immigration and contributed to its cultural diversity and commercial development.

Regular immigrants, that constitute the clear minority in Turkey or Istanbul, are a category of a huge range of different foreigners. These people, who live with legal residence and work licence in Turkey, consist of various groups such as diplomats, posted personnel and foreign wives of Turkish citizens. For example we can find German wives of Turkish citizens, or Ukrainian engineers that work for local companies.Meanwhile, irregular immigrants come primarily from the countries of the former USSR and Central Asia, and work in sectors such as domestic work, sex and entertainment. The scientific literature, however, predominantly focuses on women in the domestic sector (Pusch 2012).

Figure 3. The Situation of the Immigration in the Various Districts in Istanbul

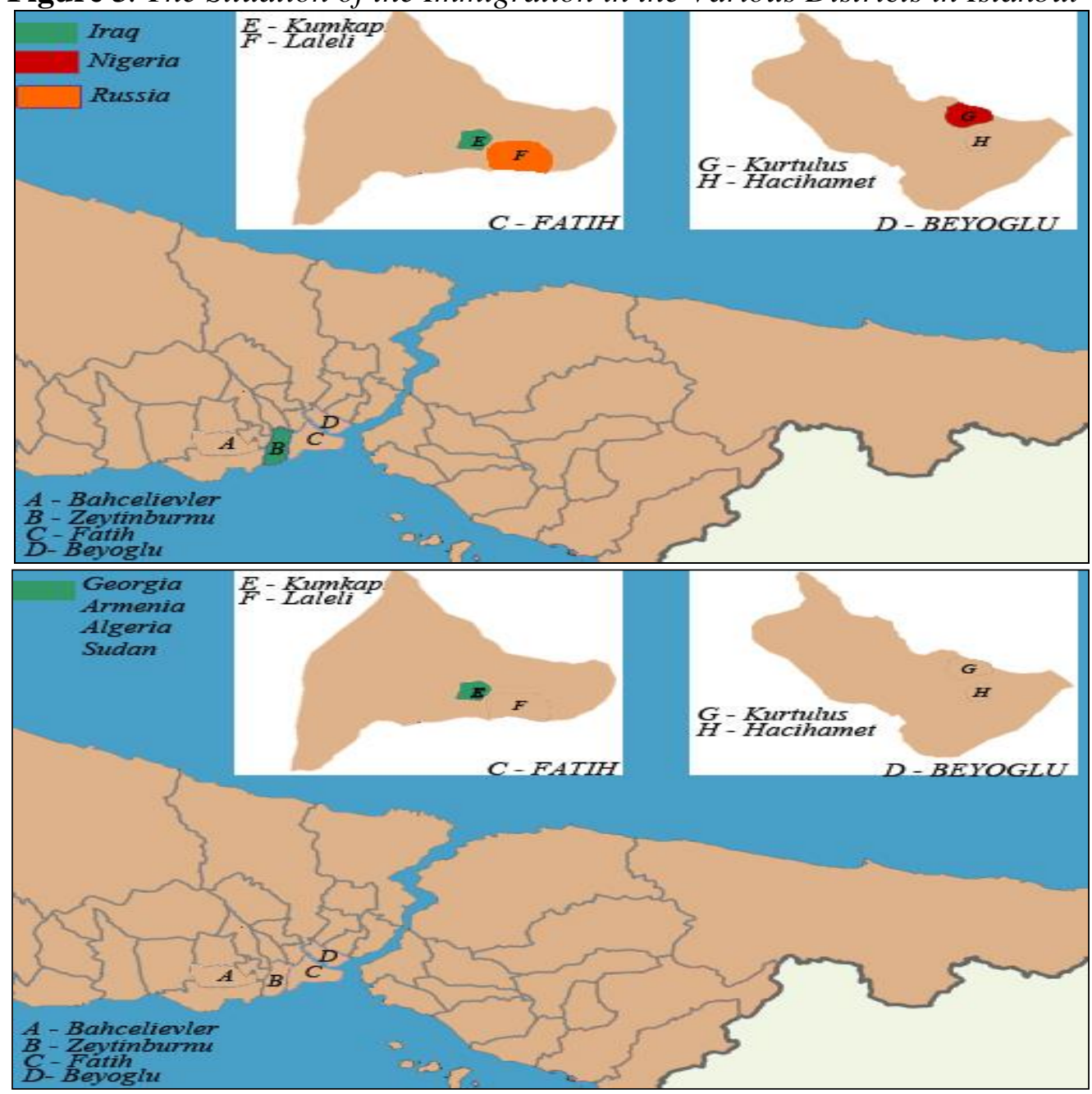

Source: Drawing by Emanuela Adamo.

For this reason, in Istanbul, like in other European cities, a solution was investigated for the actual city situation, that is vulnerable to the phenomenon of the immigration. 
As mobility increases, metropolitan areas and mainly Istanbul in the context of Turkey begin to take on different meanings for different groups. To understand what makes Istanbul what it is, the city should be seen as a dynamic knot (where population mobility, transport and economy intersect) rather than a geographical point inhabited by a certain population.

In this paper we present the proposal of a social housing settlement together with some new green areas aimed at allowing the integration of new populations in the just built reality in accordance with the bioclimatic standards.

Figure 4. Halkaii Social Housing Masterplan

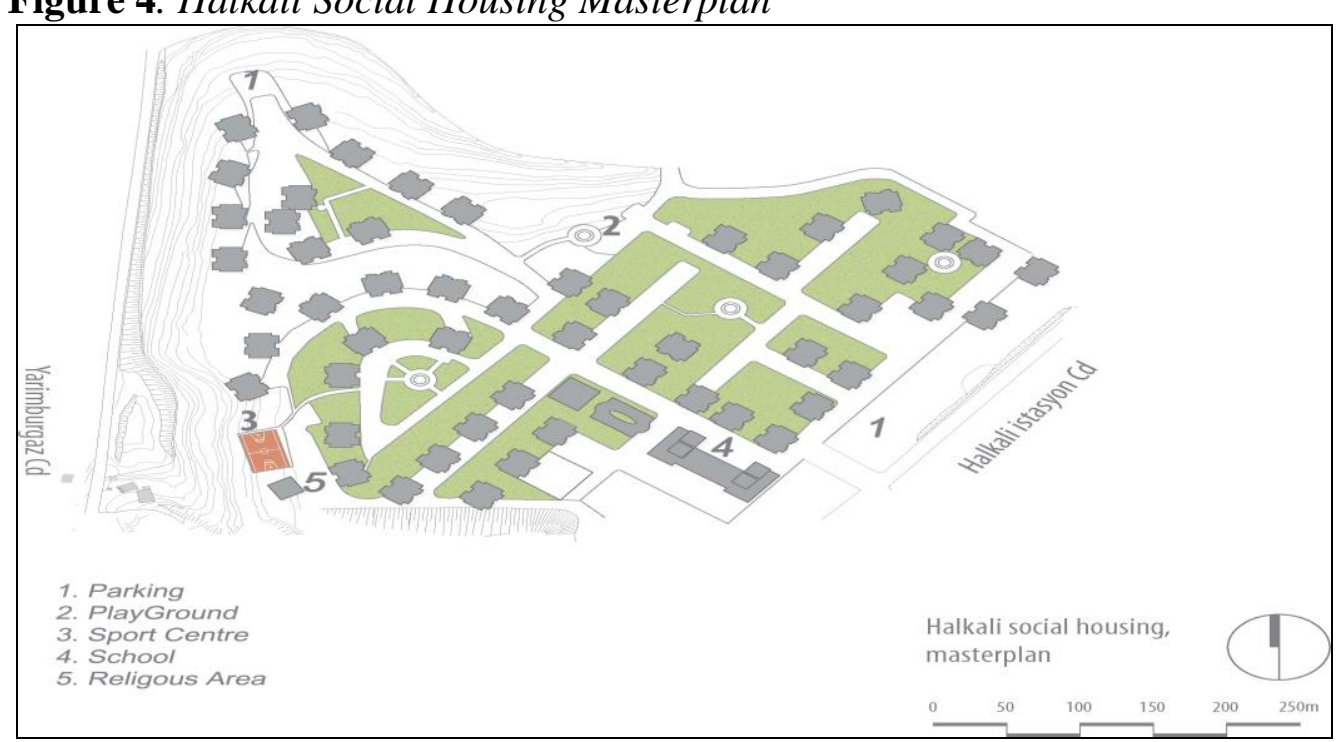

Source: Drawing by Roberta Camaggio.

Among the various concepts to be undertaken, it was important to exploit the microclimatic actions, such as the production of air clearness and life quality given by the vegetation, and also to propose the use of active solar systems, by providing passive solariums. For this last example, regular glazed elements are proposed, which are framed by wood and shadings, as elements of solar and wind control taken by the typical Turkish traditional architecture.

The selection of the typology was another important ingredient of the project. In particular, the selection of the form and the orientation of the building was due to the natural and cultural environment. In this case, all the buildings of the project had the main exposition to the South, with adequately screened transparent components, so that the solar radiation can penetrate in winter and be hindered in summer. 
Figure 5. The Exposition of the Building to South

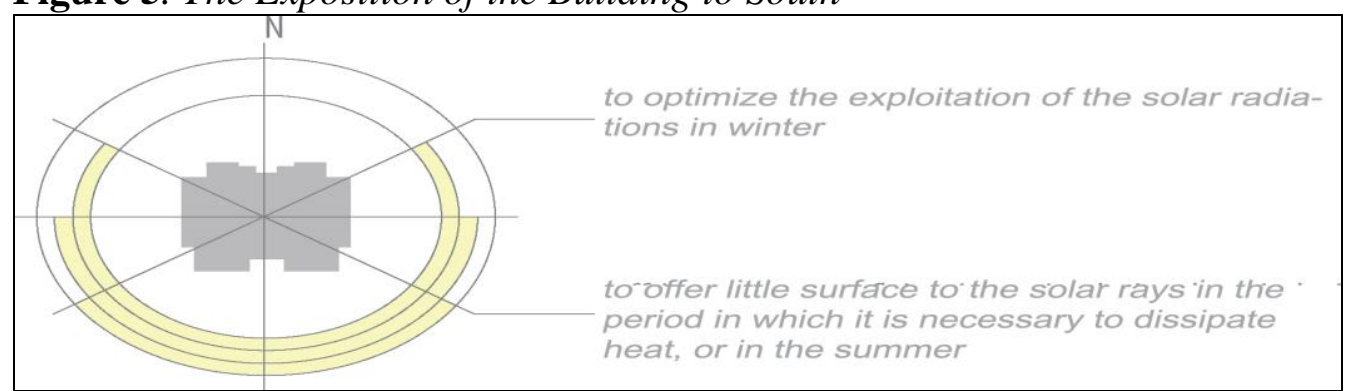

Source: Drawing by Roberta Camaggio.

With these ideas, the new typology of intervention could give an immediate answer to the problem of the refugees' needs. In particular, it improves their life conditions and creates a real part of district for the immigrants. Moreover this kind of "open space" should incentive the integration between the refugees.

In conclusion it can be affirmed that users redefine public spaces on an everyday basis through tactics; Michael De Certeau's states that the space tries to become appropriate, according to individual needs and uses. The question of what is possible within public space can be defined and described by how public space is identified; the ordinary limits of "public-ness" and public space within the geography in which we live, and our individual perceptions is shaped by social environments and historical experiences (Uzer 2010).

Designers, architects, planners, or any actor somehow producing ideas and working in relation to cities should remember that intervention into public space needs to be tackled with a perspective which will avoid discrimination and embrace everybody, and that new tactics and technologies need to be adopted for re-design.

When looking at the recent history, it is possible to talk about certain periods in the on-going discussions about the planning and design of public spaces. It can be said that the most important breaking points occurred during the period when Modernist city planning has been criticized and questioned. The urban spaces created by the Modernist approach that sees the city as an environment which can be planned and designed in its whole, became the source of important critics and arguments. In the end of the 1960s, "... participatory planning and design" came into the agenda as one of the ways out of the current congestion in the planning and architecture areas of the time. The term "public space" can be interpreted in many different ways: it is sometimes employed for signifying any exercise of land filling or transforming a site into a more beautiful place. We think instead that the public space should be considered as a site in which the fundamental requirements of actual urban quality are provided. The latter can include material urbanity, that is the ability of urban material to express civic, aesthetic, functional and social meanings (de Sola Morales 2011).

Sola-Morales asks: "... if all urban spaces are more or less public (and all public space is more or less of - or for - private interest), what would be the specificity of what we conventionally call public spaces?" (de Sola Morales 2011). 
Public space, as a combined structure of different streets and squares, is the essence, the substance of coexistence, interaction and redundancy which shared life brings with it.

The public space has this ambivalence, this capacity of allowing the experience of intimacy and sharing life with others. Given those definitions of public space, in order to design its structure, and providing places for activities, the planning discipline can help in ensuring the quality and the beauty of the final transformation. Walter Benjamin, Richard Sennett, Paul Virilio, and Fredric Jameson had often considered the public space as a sociological, political and functional phenomenon.

Public-private concepts are meaningful as long as they signify a continuous debate regarding social practices. Although it means "everywhere outside private space" such a simple definition cannot represent an avail in the case of İstanbul.

The public sphere is made up of a multitude of spaces and conversations and is shaped according to architectural ideals. However, being not only a physical space, it does not only come about as construction. The public sphere is also a basis for discussion focusing on conflicts of interests, participation and social exclusion. The urban public sphere is a physical, social and discursive space reflecting social conditions and social state.

\section{Conclusion}

The public is the space which represents power and ideology. The constant confrontation between different interests and value judgements between them actually establishes the foundation of the public sphere. The public sphere is never open to everyone in equal amount. The urban sphere, whether physical or discursive, takes on a public aspect only via contradiction and its negotiation (Actar Wildner 2008).

Currently more than half of the worlds' population lives in cities; urban areas are expanding, and their physical, social, political, ecological and cultural problems are getting more and more stratified. Metropolitan governments very often lack the sufficient budget and organizational capacity to deal with the complexities of urban settings. For this reason, selected areas of intervention, and the styles in which intervention takes place, mostly concentrate on politically meaningful and visible locations. Such issues as the participation of users to the decision-making processes of large scale urban transformation projects, which constitutes a significant aspect of democracy in the city, are either poorly undertaken, or completely skipped due to limitations of budget and time. Users on the basis of individual projects are generally considered as homogenous groups. The impact of designers, architects and urban planners on the reaction of users and the potential interaction between the users and the design can be limited. The more the scales of projects augment the probability of unexpected effects, the more irreversible interventions, that need to take place, increase. Small projects can trigger an effect at the scale of a 
neighbourhood in order to create awareness, or establish a democratic platform of discussion.

Certain concepts stand out during the program suggestions' development and in the course of the design process' projection development as summarised briefly above. Program suggestions including the scale of the spatial concept, ground-zero level relationships, proximate environment sociological data, that meet the environmental requirements, can be seen as a discovery and interpretation of the unused space's potentials within the urban fabric.

These changes of the society and thus of the urban spaces, in addition to make more comfortable this type of "staying open space", could stimulate the integration among the citizens of the hosted cities with the new populations, transform the city and promote the knowledge of the local cultural heritage.

\section{References}

Actar Wildner K (2008) Public Space2. In U Tanyeli, B Tanju, P Dervis (Eds), Becoming Istanbul. Istanbul and DAM, Frankfurt: Garanti Galery.

Castells M (2010) The Information Age: Economy, Society and Culture. End of Millennium Vol. 3. Oxford: Blackwell Publishers.

De Filippo E (2014) L'immigrazione straniera in Campania, una lettura delle presenze sulla base dei dati ufficiali [The foreign immigration in Campania, a reading of the presences based on the official data]. Retrieved from bit.ly/1P0153Z.

Joppke C (1999) Immigration and the Nation-State: The United States, Germany, and Great Britain. Oxford: Oxford University Press.

Musella M, Gualdieri G, Russo M (2008) Sulla condizione degli immigrati irregolari a Napoli [The condition of the irregular immigrants in Naples]. Prospettive Sociali e Sanitarie, 8. Retrieved from bit.ly/1KRZEAN.

Özlüdil B (2008) Migration. In U Tanyeli, B Tanju, P Dervis (Eds), Becoming Istanbul. Istanbul and DAM, Frankfurt: Garanti Galery.

Pusch B (2012) Bordering the EU: Istanbul as a Hotspot for Transnational Migration. In S Pacaci Elitok, T Straubhaar (Eds), Turkey, Migration and the EU: Potentials, Challenges and Opportunities, 167-197. Hamburg: Hamburg University Press.

de Sola Morales M (2011) The impossible project of public space. In M Angles (Ed), Favour of public space, Ten years of the European prize for urban public space. Barcelona: Centre de Cultura Contemporania de Barcelona and ACTAR.

Uzer E (2010) What is possible in public space?. In E Uzer, H T Sengun, O Karadayllar, S Soher (Eds), Imkanmekan: Small Scale Interventions in Public Space. Istanbul: Scala Matbaa. 
